\title{
Use of Celestin tube for palliation of malignant oesophageal obstruction
}

\author{
J . L. P R O V A N \\ From the Department of Surgery, University College Hospital Medical School, London, W.C.I
}

Palliation of dysphagia due to malignant obstruction of the oesophagus by passage of the Celestin tube is described in 36 cases. Although there was a high initial mortality, this was most marked when the tube was used to palliate dysphagia due to enlarged posterior mediastinal glands. Satisfactory palliation was obtained in all but one patient, and four patients survived more than six months in relatively good health. Tracheo-oesophageal fistula responded particularly well to the use of the indwelling tube. Gastro-intestinal bleeding and wound complications accounted for the main morbidity following the procedure.

Dysphagia requires palliation when the diseases which produce malignant oesophageal obstruction present at a stage when resection is not feasible or when therapy by irradiation has proved inadequate. Many attempts to produce a satisfactory form of palliative intubation have been made and the modification of the Mousseau-Barbin tube, described by Celestin in 1959, is now commonly in use. However, this form of treatment may not be effective in enabling the patient to swallow normally, while complications resulting from the combined per-oral and trans-abdominal manipulations may make the patient's remaining days less comfortable. For these reasons the notes of patients in whom this procedure had been performed were reviewed to see if Celestin intubation was an effective method of palliation.

\section{PATIENTS}

Thirty-six patients suffering from dysphagia caused by carcinoma of the oesophagus or cardia, or as a result of compression of the oesophagus by malignant glands in the posterior mediastinum, were treated by insertion of a Celestin tube between July 1960 and March 1968. Figure 1 shows the ages of these patients ; 15 of them were more than 70 years old. In 27 patients there was a definite contra-indication to resection, either because metastases were clinically apparent or because direct spread of the growth to adjacent structures prevented resection at exploration. Nine patients were too frail for exploration. At the time of operation 21 patients were able to take liquids only by mouth and regurgitation was a frequent and distressing symptom. The remaining 15 were able to swallow soft food or semi-solids. All were distressed by their dysphagia and all had lost weight.

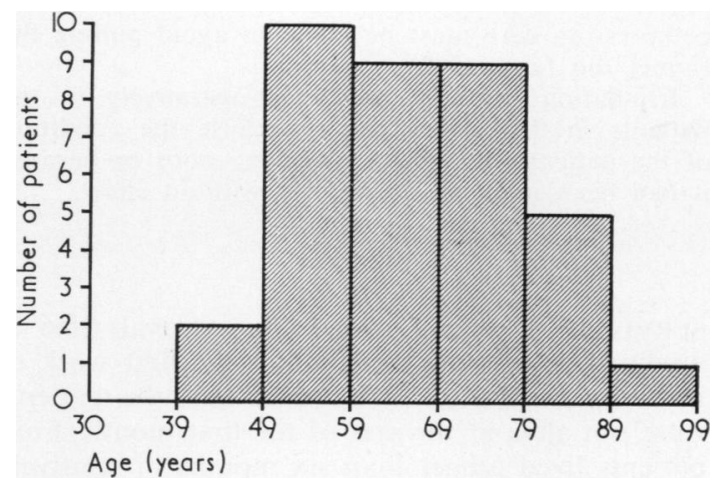

FIG. 1. Age distribution of 36 patients with dysphagia treated by Celestin intubation.

T A B L E I

TYPE OF DISEASE TREATED BY CELESTIN INTUBATION

\begin{tabular}{|c|c|c|c|}
\hline Disease & & & No. of Patients \\
\hline $\begin{array}{l}\text { Primary carcinoma oesophagus } \\
\text { Primary carcinoma stomach } \\
\text { Post-resection stricture } . \\
\text { Posterior mediastinal glands }\end{array}$ & $\begin{array}{l}\cdots \\
\cdots \\
\cdots\end{array}$ & $\begin{array}{l}\cdots \\
\cdots \\
\cdots\end{array}$ & $\begin{array}{r}16 \\
9 \\
1 \\
10\end{array}$ \\
\hline Total & . & $\ldots$ & 36 \\
\hline
\end{tabular}

Table I shows the type of disease that caused dysphagia. There were 16 cases of primary squamous carcinoma of the oesophagus and 10 of carcinoma which arose in or invaded the cardia and which were shown histologically to be adenocarcinoma. One of the patients with carcinoma of the stomach had the tube inserted because of dysphagia due to malignant stricture of the oesophago-gastric anastomosis following gastrectomy. The remaining 10 patients had carcinoma of the bronchus with metastatic involvement of the posterior mediastinal glands producing dys- 
phagia. In these 10 the primary disease had been treated earlier by irradiation or resection, but subsequent radiotherapy to the glands had not improved the ability of the patient to swallow.

Three patients had a malignant tracheo-oesophageal fistula.

\section{TECHNIQUE}

The tube is inserted as described by Celestin (1959). A preliminary oesophagoscopy is required to show the upper level of the obstruction and dilatation of a stricture may be needed. Care is necessary when introducing the tube to follow it with the oesophagoscope so that buckling of the funnel can be detected and further traction on the tube stopped. If the upper limit of the stricture appears to extend higher on the anterior or posterior wall of the oesophagus that portion of the funnel of the Celestin tube may be cut away prior to introduction. This will prevent buckling of the rim and possible obstruction to swallowing. With the more elastic strictures due to extrinsic compression care must be taken to avoid pulling the funnel too far into the stricture.

Irradiation was not used post-operatively in the patients in this series, either because the condition of the patient was judged to be too poor or because it had been used pre-operatively without effect.

\section{RESULTS}

SURVIVAL Figure 2 shows the survival time in weeks. Ten patients died within the first week of insertion of the tube and over half the patients were not alive at the end of the first month. Four patients lived longer than six months in relatively good health and the longest survivor died eight and a half months after insertion of the tube. The precise cause of death was only ascertained by necropsy in a few patients. Most patients died of pneumonia or metastases.

If the three main groups of patients are subdivided from the point of view of survival (Table II) it can be seen that the use of the tube in those with dysphagia due to the presence of posterior mediastinal glands carried a worse prognosis than when it was used to palliate primary carcinoma of either the oesophagus or the cardia. Seven of the 10 patients with mediastinal glands died within three weeks of insertion of the tube and none

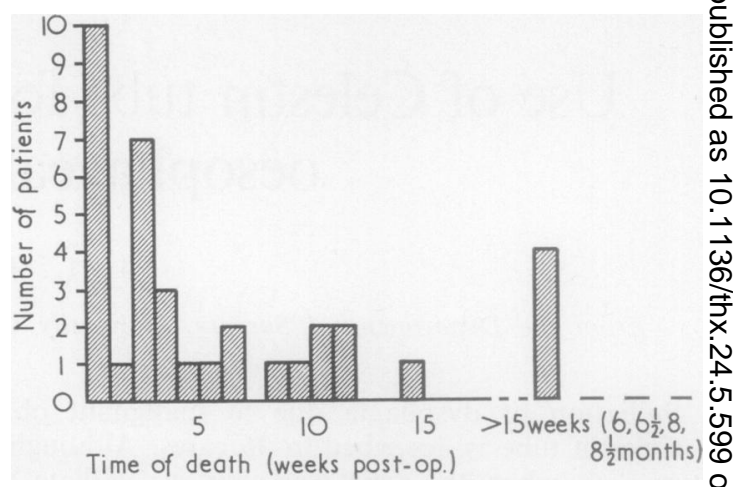

FIG. 2. Time of death after insertion of Celestin tube.

lived longer than five weeks. With primary car $\frac{\mathbb{D}}{\mathbb{O}}$ cinoma of the oesophagus eight of 16 patients dieक within three weeks, but thereafter the prognosid was better with two patients surviving more than. six months. Three of 10 patients with adeno\& carcinoma at the cardia died within three week $\$$ of intubation, but five of the remainder survive $\$$ more than three months and two more than sie months.

COMPLICATIONS Only 16 patients had a post? operative course which was described in the note as uncomplicated. Table III lists the frequency o complications. In one patient who was not imb proved failure resulted from positioning the tube too low in a distensible stricture due to extrinsict compression of the oesophagus by glands. In the other instance, dysphagia rapidly recurred aftef relief of symptoms ; this case is discussed below. $\overline{0}$

Bleeding occurred in five patients and produce rapid death from a massive gastro-intestina haemorrhage in three cases. In two of these the gastric end of the tube had produced erosion $\propto$ the stomach, while in the third death was caused by rupture of a pulmonary artery aneurysm whic was thought to be mycotic in origin and associate with erosion of the oesophagus by the wide uppes end of the tube with formation of a mediastinal abscess.

Wound infection occurred in four patients. required dressing only and did not lead to wound

T A B L E I I

TIME OF DEATH AFTER INSERTION OF CELLESTIN TUBE RELATED TO AETIOLOGY OF DYSPHAGIA

\begin{tabular}{|c|c|c|c|c|c|c|c|c|c|c|c|c|c|c|c|}
\hline \multirow{2}{*}{\multicolumn{2}{|c|}{ Disease }} & \multicolumn{14}{|c|}{ No. of Patients Dying each Week after Insertion of Tube } \\
\hline & & 1 & 2 & 3 & 4 & 5 & 6 & 7 & 8 & 10 & 12 & 16 & 20 & 24 & $1>24$ \\
\hline $\begin{array}{l}\text { Primary carcinoma oesophagus } \\
\text { Primary carcinoma stomach... } \\
\text { Posterior mediastinal glands }\end{array}$ & $\begin{array}{l}\cdots \\
\cdots\end{array}$ & $\begin{array}{l}5 \\
1 \\
3\end{array}$ & $\begin{array}{l}0 \\
0 \\
2\end{array}$ & $\begin{array}{l}3 \\
2 \\
2\end{array}$ & $\begin{array}{l}0 \\
1 \\
2\end{array}$ & $\begin{array}{l}0 \\
0 \\
1\end{array}$ & $\begin{array}{l}1 \\
0\end{array}$ & $\begin{array}{l}1 \\
1\end{array}$ & 0 & $\begin{array}{l}\mathbf{0} \\
\mathbf{0} \\
\mathrm{A}\end{array}$ & $\begin{array}{r}3 \\
0 \\
\text { dead }\end{array}$ & $\mathbf{0}$ & $\begin{array}{l}0 \\
0\end{array}$ & $\begin{array}{l}1 \\
0\end{array}$ & 2 \\
\hline
\end{tabular}


T A B L E I I I

COMPLICATIONS OF INSERTION OF CELESTIN TUBE IN 36 CASES

\begin{tabular}{|c|c|c|c|}
\hline $\begin{array}{l}\text { Dysphagia unrelieved } \\
\text { Gastrointestinal bleeding } \\
\text { Wound infection } \\
\text { Wound disruption } \\
\text { Oesophagitis } \\
\text { Oesophageal perforation } \\
\text { Reoperation } \\
\text { Others (myocardial infarc } \\
\text { thrombosis, pulmonary }\end{array}$ & $\begin{array}{ll}\cdots & \cdots \\
\cdots & \cdots \\
\cdots & \cdots \\
\cdots & \cdots \\
& \cdots \\
\text { ction, deep } \\
\text { embolism) }\end{array}$ & $\begin{array}{c}\ldots \\
\cdots \\
\ldots \\
\cdots \\
\text { vein } \\
\ldots\end{array}$ & $\begin{array}{l}1 \\
5 \\
4 \\
3 \\
2 \\
5 \\
1\end{array}$ \\
\hline
\end{tabular}

disruption. This complication did occur in three other patients, none of whom required resuture.

Two patients complained of heartburn due to reflux oesophagitis. This responded to antacids and keeping the patient propped up.

At operation the oesophagus was perforated on two oscasions. In one patient this led to death on the second post-operative day, but the other survived until the third week. In three other patients the pilot bougie entered the stomach submucosally and the mucosa had to be incised to permit extraction of the bougie and fixation of the tube. In no case did complications ensue as a result of this manœuvre. Two other patients, dying respectively in the third and seventh post-operative weeks, were noted at necropsy to have a mediastinal abscess from perforation of the growth by the funnel of the tube. In each case introduction had been uneventful.

Although pneumonia was frequently noted in patients who died in hospital, other systemic illnesses were rare in view of the age and poor general state of many of the patients. Deep vein thrombosis was noted in only two patients, while one patient died of a massive pulmonary embolus and one of myocardial infarction.

RESTORATION OF SWALlowing (Table IV) Relief of symptoms was assessed in all patients except in four who died before this could be done. Of the remainder, only two obtained no palliation of their dysphagia. Although half the patients died within three weeks of insertion of the tube their swallowing was improved during the time they were alive.

Prior to operation 21 of the 36 patients were able to swallow liquids only. In some of these, dysphagia was almost complete and regurgitation

T A B L E I V

RESTORATION OF SWALLOWING ABILITY

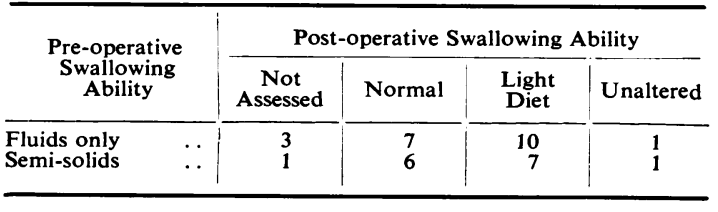

was troublesome. Seventeen of these patients were definitely improved in that normal swallowing was restored in seven, while 10 were able to manage a light diet without dysphagia. Three died before an assessment could be made, and in one dysphagia recurred. He was re-explored a month later after radiography had shown a block at the lower end of the tube. This was found to be due to glands around the coeliac axis. The tube was readjusted and he was discharged eating a light diet.

Fifteen patients were able to swallow semisolids before insertion of the Celestin tube. Six were restored to normal swallowing and seven were sufficiently improved to manage a light diet without dysphagia. One patient in this group, who died in the immediate post-operative period, was not assessed, and one gradually deteriorated to die after three weeks. The latter patient was not improved and has been mentioned above.

TRACHEO-OESOPHAGEAL FISTULA There were three patients with tracheo-oesophageal fistula causing distressing symptoms. One patient died on the day after operation from haemorrhage and inhalation of blood. The second survived for eight days and during this time ate a complete Christmas dinner. The third patient died nine weeks after operation, having been swallowing normally during much of this time.

\section{DISCUSSION}

In order to be acceptable a palliative procedure must relieve symptoms with minimal morbidity. If the disease which is being palliated is a fatal one with distressing terminal symptoms a high mortality may be accepted in an attempt to relieve such symptoms. This is the case with carcinoma of the oesophagus or stomach causing dysphagia. Resection may not be possible because of local involvement, while in other cases the poor general condition of the patient will not permit the thoraco-abdominal operation that is required to bypass an obstructive lesion. Even in those cases where a jejunal bypass is performed, palliation may not be satisfactory and a mortality of up to $60 \%$ has been reported by Barnard, Kilroy, and Kennedy (1966). Palliation for dysphagia, using a long tube of the Mousseau-Barbin or Celestin type, has in general been more successful than the use of the Souttar tube, which frequently became dislodged or blocked. In the present series, $28 \%$ of the $\mathbf{3 6}$ patients died within the first week while $50 \%$ were dead within three weeks. However, the prognosis was far worse when intubation was used to palliate dysphagia due to posterior mediastinal 
glands, as no patient with this diagnosis survived more than five weeks following insertion of the tube. Although there was an appreciable mortality within three weeks in those with carcinoma of the oesophagus or cardia, several patients survived for more than six months in relatively good health. All those patients who survived more than three weeks left hospital, if only for a while. This distinction between the type of disease treated by Celestin intubation has not been made before. It suggests that palliation of dysphagia due to the presence of glands in the posterior mediastinum due to metastatic carcinoma may not be justified in view of the poor prognosis of patients who have such glandular involvement.

Satisfactory palliation, judged by relief of dysphagia and by improvement in the type of diet, was obtained in 29 of the 31 patients in whom this could be assessed. It has been noted that few returned to a normal diet, although post-operative dysphagia was noted by only two patients. Many of these seriously ill patients were in the terminal stage of their disease and even with dysphagia relieved were anorexic or able to tolerate only a light diet. In terms of symptomatic relief the Celestin tube has proved to be effective while the high mortality is, I suggest, acceptable when the indications for this operation are clear.

The morbidity is also acceptable. Only two patients died from myocardial infarction or pulmonary embolism. Wound disruption occurred three times, was of only minor degree, and occurred less frequently than might have been expected in a group of patients who were undernourished and suffering from malignant disease.

The incidence of gastro-intestinal bleeding is high and may be due to faulty positioning of the tube at the lower end. In several cases at necropsy there was either an ulcer adjacent to the sharp lower end of the tube or else the braided nylon holding suture had cut out. Both these events may cause bleeding and it is important to cut the tube as high up the stomach as possible and tie the holding suture loosely.

Oesophagitis as a result of the abolition of the anti-reflux mechanism was not a problem. Few patients complained of heartburn or reflux but all were told to avoid bending and to sleep propped up. Similarly, bolus obstruction of the tube was infrequent as long as plenty of liquid was taker with food and if fizzy drinks were used regularlyo to clean out the tube.

In two of the three cases of tracheo-oesophagea $\stackrel{\mathbb{R}}{\Omega}$ fistula, where symptoms were distressing, adequates palliation was obtained. These patients were able to swallow fluid and food without coughing, and in one patient the severe basal pneumonix. improved dramatically.

In cases in which resection is contraindicated palliation by means of the Celestin tube is ade $-\rightarrow$ quate. When compared with an operative morier tality of $20 \%$ for resection in fit patients with short history, and a five-year survival rate of about $5 \%$, the high mortality following insertion of the tube is acceptable. Comparative figures for $\vec{c}$ oesophageal intubation are not easily available $\mathbb{D}$ but Carter and Hinshaw (1963) reported 20 case treated by Celestin intubation, with an operative mortality of $20 \%$. Barnard et al. (1966) noted nod mortality in 10 patients up to four weeks follow $\vec{C}$ ing insertion of the Mousseau-Barbin tube. The्g morbidity is seldom such as to make the patients remaining days more miserable than before operation. Wound disruption and gastric ulceras tion have been noted by Fell, Grunwald, an $\bar{\Phi}$ Hurwitt (1966), who modified the Celestin tube tळ̊ avoid this hazard. Barnard and his colleagues (1966) had two cases of gastrointestinal hae $\overrightarrow{\overrightarrow{0}}$ morrhage in their 10 cases. It is likely that the Celestin tube now commercially available, which is made of softer rubber rather than natural poly? thene, will reduce the hazard of gastric ulceration

The majority of the patients reported above were under the care of Professor R. S. Pilcher or Misso Doreen Nightingale. I am grateful to them, and also to Mr. D. A. Bailey, Mr. G. L. Bunton. Mr. D. R Davies, and Mr. H. R. I. Wolfe for permission tos study their cases.

\section{REFERENCES}

Barnard, P. M., Kilroy, E. G., and Kennedy, J. H. (1966). Inoperable cancer of the esophagus: use of the Mousseau-Barbin tube in palliative surgery. J. thorac. cardiovasc. Surg., 51, 125.

Carter, R., and Hinshaw, D. B. (1963). Use of the Celestin indwelling plastic tube for inoperable carcinoma of the esophagus and cardia Surg. Gynec. Obstet., 117, 641 .

Celestin, L. R. (1959). Permanent intubation in inoperable cancer of the oesophagus and cardia. Ann. roy. Coll. Surg. Engl., 25, 165

Fell, S. C., Grunwald, R. P., and Hurwitt, E. S. (1966). Palliation esophageal carcinoma by prosthetic intubation. J. thorac. cardiof vasc. Surg., 51, 272. 